\title{
Implementasi Perpustakaan Digital TV Sekolah sebagai Dokumen Otentik bagi TK Insan Profesi Baubau
}

\author{
Mariasi $^{1}$, Sri Watini ${ }^{2}$ \\ 1,2Universitas Panca Sakti, Bekasi, Indonesia \\ E-mail: assymariasi@gmail.com,srie.watini@gmail.com
}

\begin{abstract}
Article Info
Abstract

Article History

School TV is a mobile TV service that is used by schools as a learning medium. Key

Received: 2022-02-03

Revised: 2022-02-22

Published: 2022-03-01

Features in School TV are School Stage, Digital Library, School TV Festival and Virtual Classroom. This research aims to describe the Implementation of the School TV Digital Library as an Authentic Documentation at Baubau Professional Kindergarten which is located at Jalan Gatot Subroto RT. 001 RW. 004 Bukit Wolio Indah Village Wolio

Keywords: School TV;

Digital Library;

Authentic Document. District of Southeast Sulawesi Province. This research uses qualitative descriptive methods. School TV comes with the tagline "learning and creative rides that have features including School Stage, Digital Library, Virtual Classroom and School TV Festival. The Digital Library feature presents educational videos of school activities carried out by schools, teachers and students. TK Insan Profesi has documentetion school activities to feature the School Digital Library which becomes an authentic school file or document that is not a school.
\end{abstract}

\begin{tabular}{l}
\hline Artikel Info \\
\hline Sejarah Artikel \\
Diterima: 2022-02-03 \\
Direvisi: 2022-02-22 \\
Dipublikasi: 2022-03-01
\end{tabular}

Kata kunci:

TV Sekolah; Perpustakaan Digital; Dokumentasi Otentik.

\begin{abstract}
Abstrak
TV Sekolah merupakan media layanan tv mobile yang dimanfaatkan oleh sekolah sebagai media pembelajaran. Fitur Utama dalam TV Sekolah adalah Panggung Sekolah, Perpustakaan Digital, Festival TV Sekolah dan Kelas Virtual. Penelitian ini bertujuan untuk mendeskripsikan Implementasi Perpustakaan Digital TV Sekolah sebagai Dokumentasi Otentik pada TK Insan Profesi Baubau yang beralamat di Jalan Gatot Subroto RT. 001 RW. 004 Kelurahan Bukit Wolio Indah Kecamatan Wolio Provinsi Sulawesi Tenggara. Penelitian ini menggunakan metode deskriptif kualitatif. TV Sekolah hadir dengan tagline "wahana belajar dan berkreasi yang memiliki fitur antara lain Panggung Sekolah, Perpustakaan Digital, Kelas Virtual dan Festival TV Sekolah. Fitur Perpustakaan Digital menyajikan video edukatif kegiatan sekolah yang dilakukan oleh sekolah, guru dan murid. TK Insan Profesi telah mendokumentasikan vidio-vidio kegiatan sekolah ke fitur Perpustakaan Digital Sekolah yang menjadi file atau dokumentasi otentik sekolah yang tidak akan punah atau hilang sampai kapanpun, serta dapat diakses oleh siapa saja dan waktu akses fleksibel.
\end{abstract}

\section{PENDAHULUAN}

Televisi Salah satu media Audio Visual yang sangat digemari oleh masyarakat pada umumnya, sejak zaman dulu samapai sekarang Televisi yang pertama kali ditonton oleh masyarakat Indonesia adalah Televisi Republik Indonesia (TVRI), dengan berkembangnya era tekhnologi maka banyak bermunculan namanama televisi swasta yang menjadi tontonan masyarakat mulai dari Indosiar, SCTV, RCTI, TransTV, Metro TV, TVone, Kompas TV dan masih banyak lagi televisi swasta lainnya. Televisi dapat kita jumpai hampir disetiap rumah, program yang ditawarkan sangat bermacam-macam mulai dari program edukasi, spiritual, olahraga, discovery, drama, film pendek atau sinetron dan program-program lainnya, menurut Arief Budiman (2017) Televisi adalah sebuah teknologi yang sangat berpengaruh dalam perkembangan teknologi informasi di seluruh dunia. Pada awal perkembangannya, televisi adalah gabungan teknologi optik mekanik dan elektronik yang digunakan untuk merekam, menampilkan dan menyiarkan gambar visual.

Di dunia pendidikan Indonesia dibawah naungan Kementerian Pendidikan dan Kebudayaan juga menawarkan media pembelajaran mulai dari pendidikan anak usia dini bahkan sampai tingkat menengah atas yaitu Balai Pengembangan Media Televisi Pendidikan dan Kebudayaan (BPMTPK), yang dikonsusmi oleh para pengajar/pendidik dan para pelajar/siswa. Balai pengembangan media televisi pendidikan dan kebudayaan adalah unit pelaksana teknis Kementerian Pendidikan dan Kebudayaan di bidang pengembangan media vidio dan televisi pendidikan dan kebudayaan yang berada dibawah dan bertanggung jawab kepada Kepala Pusat Data dan Teknologi Informasi (2018). Dari sekian banyak media televisi tersebut ada salah 
satu media televisi yang sedang dikembangkan oleh Forum menjadi layanan publik bagi orang tua, guru dan siswa yang fiturnya setara dengan perangkat milyaran dari stasiun televisi swasta, media ini disebut TV Sekolah. TV Sekolah merupakan layanan streaming untuk semua sekolah hasil revolusi industri 4.0 yang tidak memerlukan perangkat fisik apapun di sekolah, cukup dengan sebuah benda kecil yang dibawa kemana-mana seperti HP/Gadged, laptop, notebook untuk menyusun playlist yang akan ditampilkan, dengan menggunakan alat tersebut maka sekolah sudah dapat memiliki sebuah master control stasiun TV lengkap, karena setiap sekolah yang telah mendaftar di TV Sekolah dapat menyelenggarakan siaran sendiri dengan video yang telah dibuat dan yang dimiliki oleh sekolah dengan cara menyusun playlist. Setelah menyusun playlist maka video siap ditonton oleh siapapun baik ditonton oleh sekolah itu sendiri maupun orang lain. TV Sekolah juga menyediakan platform pembelajaran digital yang berbasis video dengan memanfaatkan konten video yang ada dalam perpustakaan digital TV Sekolah.id.

TV Sekolah dapat diaplikasikan dengan mudah oleh siapapun, karena dijamin aman dan konten-kontennya bernilai edukatif, dilengkapi dengan Chanel guru yang berisi Modul Pembelajaran berbasis video yang biasa diambil dari Youtube yang telah diplaylist oleh verifikator sekolah, salah satu fitur Utama TV Sekolah adalah Perpustakaan Digital. Perpustakaan digital atau Digital Library adalah suatu perpustakaan yang menyimpan data baik itu buku (tulisan), gambar, suara dalam bentuk file elektronik dan mendistribusikannya dengan menggunakan protocol elektronik melalui jaringan komputer. Istilah Perpustakaan digital atau digital library itu sendiri mengandung pengertian sama dengan electronic library dan virtual library. Sedangkan menurut istilah yang sering digunakan dewasa ini adalah digital library, bahkan di dalam suatu sistem web based learning atau virtual classroom, banyak pihak menyebut sistem belajar melalui internet.

Perpustakaan digital atau digital library adalah gabungan ICT (Information and Communication Technology) dengan isi dan program yang dibutuhkan untuk mereproduksi dan mengembangkan layanan yang biasa disediakan oleh perpustakaan konvesional yang berbasis kertas atau material lainnya. Seiring dengan kemajuan teknologi Perpustakaan digital mulai berkembang pesat sejak tahun 1990 melalui jaringan komputer yang pengaksesan informasi dari satu tempat ke tempat lain sangat cepat dalam waktu sekejap.

Menurut William Arms (2007) mengatakan bahwa perpustakaan digital adalah kumpulan informasi yang tersusun baik beserta layananlayanan yang disediakan dan disimpan dalam format digital untuk diakses melalui jaringan komputer. Ridwan Siregar (2004) mengatakan bahwa perpustakaan digital adalah lingkungan perpustakaan di mana berbagai objek informasi seperti dokumen, gambar, suara dan video yang disimpan dan diakses dalam bentuk digital. Sedangkan Perpustakaan digital dalam fitur TV Sekolah yang dikembangkan oleh Sri Watini, dkk (2020) bahwa merupakan fitur TV Sekolah yang menyajikan tayangan-tayangan vidio edukatif kiriman siswa dan guru dari seluruh indonesia. Video akan didokumentasikan ke dalam file Dokumen Perpustakaan Digital TV Sekolah yang dapat diakses oleh siswa-siswi maupun guru baik dari sekolah yang bersangkutan maupun dari sekolah lain. TV Sekolah yang dikembangkan oleh Sri Watini dkk, sudah memiliki Hak Cipta yang telah terdaftar hak paten no. EC00202040424, tanggal 15 Oktober 2020 dengan Nomor pencatatan 000224874, serta telah terdaftar dalam PSE dengan nomor 002009.01/DJAI.PSE/01/2022, pada 25 Januari 2022 sebagai TV Sekolah Wahana Kreasi.

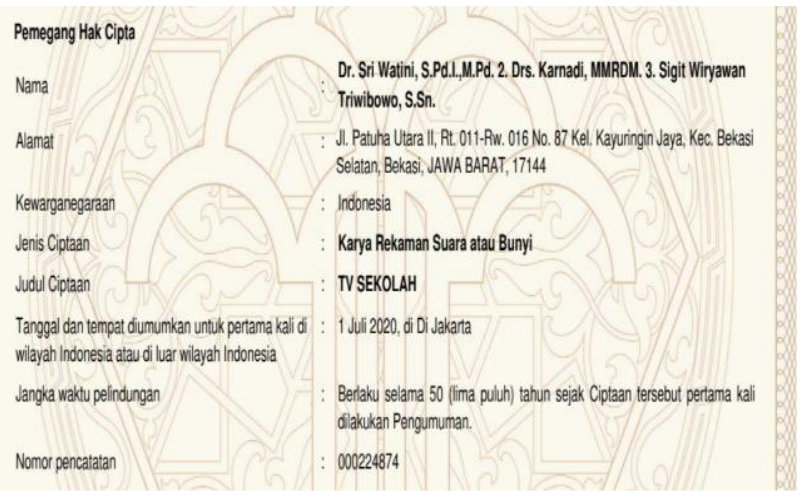

Gambar 1. Hak Cipta TV Sekolah

Penelitian ini bertujuan pertama, untuk mendeskripsikan Implementasi Perpustakaan Digital TV Sekolah sebagai Dokumentasi Otentik pada TK Insan Profesi Baubau. Kedua untuk memotivasi guru dalam mendokumentasikan setiap kegiatan yang dilakukan baik itu dalam proses belajar dikelas maupun diluar kelas secara otentik. Ketiga untuk memberikan semangat kepada anak-anak TK Insan Profesi dalam melakukan kegiatan belajar maupun bermain, baik itu dilakukan di sekolah maupun 
dilakukan di rumah. Keempat untuk memberikan informasi kepada orang tua murid tentang kegiatan anak-anak atau kegiatan sekolah tempat anak-anak belajar atau bermain.

\section{METODE PENELITIAN}

Penelitian ini menggunakan pendekatan metode deskriptif kualitatif, Adapun waktu penelitian dimulai sejak bulan Oktober sampai bulan Februari, yang bertempat di TK Insan Profesi Baubau yang beralamat di Jalan Gatot Subroto RT. 001 RW. 004 Kelurahan Bukit Wolio Indah Kecamatan Wolio Provinsi Sulawesi Tenggara. Adapun subjek dalam penelitian ini adalah kegiatan guru, murid dan orang tua murid yang menjadi bahan untuk dokumentasi.

\section{HASIL DAN PEMBAHASAN}

TV Sekolah dengan alamat website https://tvsekolah.id adalah layanan Chanel TV yang dikembangkan oleh Dr. Sri Watini, M.Pd (CEO), Drs. Karnadi, MRDM (CIO) dan Sigit W. Triwibowo, S.Sn (CTO) Hardianto, M.Kom (CTO), Syarif Hidayatullah, S. Pd (CMO) serta yang tergabung dalam Forum Dosen Guru dan Masyarakat (Fordorum) sebagai asosiasi terpadu antara semua komponen yang mencoba untuk memberikan alternativ model pembelajaran yang ASYIK "Aman, Senang, Yakin dan Percaya Diri, Inovatif dan Kreatif" dengan menghadirkan TV Sekolah Fordorum sebagai Sarana Belajar dan Berkreasi dari semua jenjang sekolah mulai dari PAUD sampai tingkat Perguruan Tinggi.

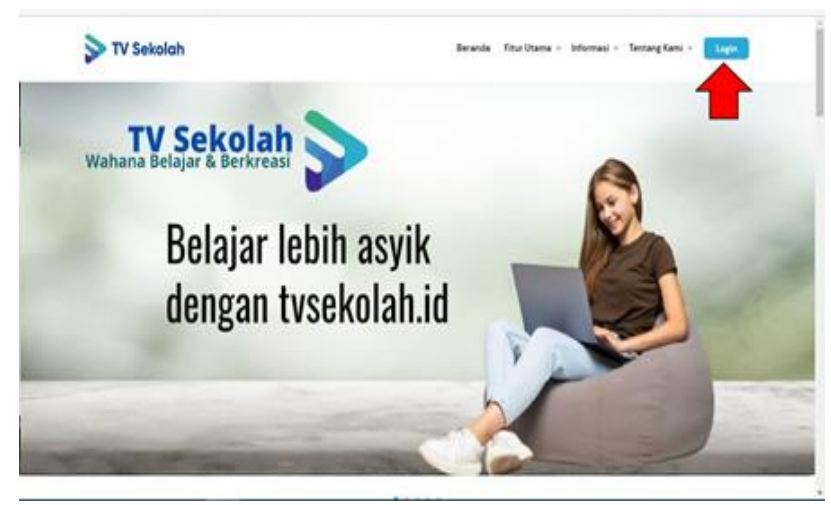

Gambar 2. Buka halaman tvsekolah.id: Klik Login

Adapun Fitur Utama yang adal dalam TV Sekolah yaitu :

1. Panggung Sekolah

Panggung Sekolah merupakan Chanel TV streaming yang dikembangkan sendiri oleh masing-masing sekolah dengan menampil-kan berbagai hal edukatif terkait kegiatan- kegiatan sekolah yang menjadi programprogram unggulan oleh sekolah tersebut, programnya dapat disusun oleh sekolah mulai hari senin sampai hari minggu.
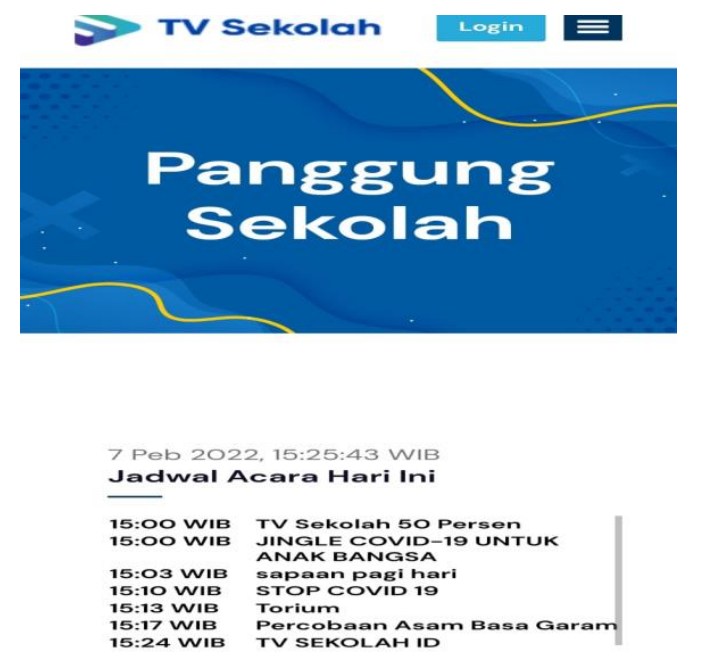

Gambar 3. Fitur Panggung Sekolah

2. Perpustakaan Digital

Perpustakaan Digital adalah fitur TV Sekolah yang menyajikan tayangan-tayangan video edukatif yang dibuat siswa dan guru dari selurh indonesia. Video akan didokumentasikan ke dalam file dokumen Perpustakaan TV Sekolah yang dapat diakses oleh siswa-siswa maupun guru-guru bahkan oleh orang tua siswa itu sendiri bahkan juga dapat diakses oleh sekolah lain, konten-konten video dalam Perpustakaan Digital dapat berupa pre-sentasi pembelajaran, kisah sukses seorang tokoh, kegiatan siswa dan guru, kegiatan parenting dapat didokumentasikan.

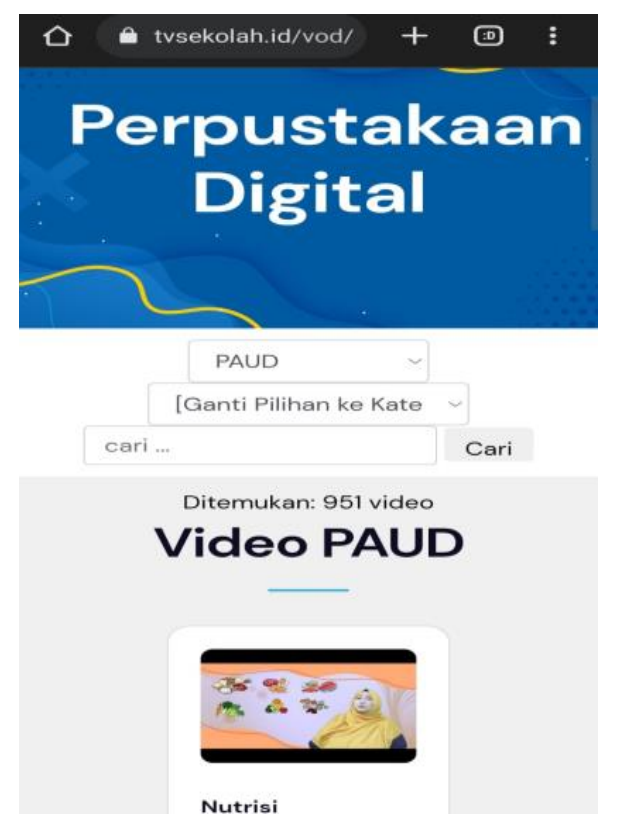

Gambar 4. Fitur Perpustakaan Digital 
3. Festival TV Sekolah

Fitur Festival TV Sekolah sebagai aplikasi yang menyajikan gamifikasi atau teknik desain permainan, yang menyediakan wahana kompetisi baik bagi lembaga/sekolah, guru maupun siswa secara positif baik dilaksanakan di tingkat Kabupaten/kota, provinsi, nasional, ASEAN maupun Internasional, sehingga dapat mengakomodosi munculnya potensi-potensi hebat, berkarakter, kompetitif dan professional. Kemampuan membuka diri dan berkompetisi secara terbuka saat ini akan menjadi wujud eksistensi seseorang dalam hal ini baik siswa maupun guru di sekolah. Semoga Festival TV Sekolah sebagai fitur yang menyediakan kompetisi dapat mengakomodasi munculnya potensi-potensi anak yang baik.

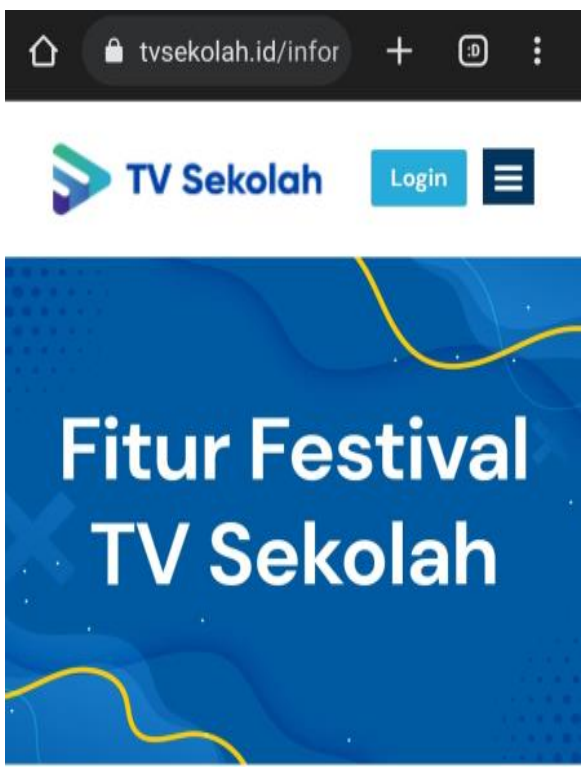

Gambar 5. Gambar Fitur Festival TV Sekolah

4. Kelas Virtual

Fitur ini menjadi kelas unggulan TV Sekolah yang telah diluncurkan setahunnya yang lalu tepatnya pada tanggal 1 Januari 2021, kelas Virtual ini berisis Program Micro Learning yang disusun oleh guru dalam waktu yang singkat untuk persiapan proses pembelajaran daring. Dalam format program ini diharapkan dapat mengakomodasi berbagai gaya belajar siswa baik visual, audoty maupun kinestetik.

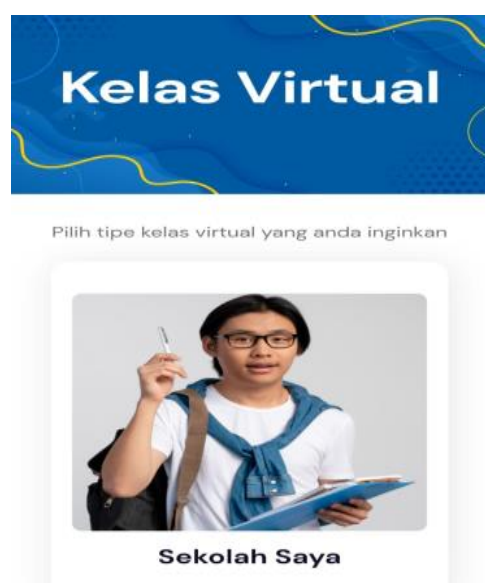

Gambar 6. Gambar Fitur Kelas Virtual

Fitur-fitur itulah yang mewarnai program TV Sekolah yang dikembangkan oleh sekolahsekolah yang telah terdaftar dalam Chanel TV Sekolah. TV Sekolah telah membawa manfaat buat Lembaga Pendidikan TK Insan Profesi Kota Baubau sejak terdaftar dalam Chanel TV Sekolah pada bulan Oktober 2021 lalu. Chanel TV Sekolah Lembaga Pendidikan TK Insan Profesi yaitu: https://tvsekolah.id/chanel/ sekolah/ch69918339. Adapun cara mendokumentasikan Video-video kegiatan anakanak, guru maupun kegiatan parenting orang tua murid adalah pertama-tama video diapload ke YouTobe chanel Sekolah TK Insan Profesi, kemudian verikator menyusun playlist video dengan cara menyalin link video kegiatan yang ada di chanel YouTobe sekolah. dikirim ke Chanel TV Sekolah TK Insan Profesi mulai hari senin sampai hari minggu. Setelah itu chanel TV Sekolah sudah dapat ditonton oleh guru, anak-anak dan orang tua murid TK Insan Profesi.

Dengan adanya chanel TV Sekolah guru termotivasi untuk selalu mendokumentasikan kegiatan-kegiatan pembelajaran-nya bersama anak-anak maupun dengan orang tua murid melalui video, untuk menjadi dokumen asli TK Insan Profesi yang difilekan kedalam Perpustakaan Digital TV Sekolah. File atau dokumen yang telah tersimpan tidak akan hilang sampai kapanpun, sehingga jika sewaktu-waktu dibutuhkan maka sekolah cukup membuka Chanel TV Sekolah Lembaga Pendidikan TK Insan Profesi https://tvsekolah.id/chanel/ sekolah/ch69918339 Perpustakaan Digital TV Sekolah sangat mudah diakses oleh siapa saja mulai jenjang Pendidikan Anak Usia Dini, sampai ke tingkat Perguruan Tinggi. Konten 
video dalam perpustakaan digital dapat berupa presentasi seorang tokoh, kisah sukses seorang tokoh, kesehatan, ragam budaya, lagu-lagu anak, motivasi para tokoh pendidikan dan lain-lain. Atau dapat disesuaikan dengan tingkat kebutuhan masing-masing sekolah serta kebutuhan guru, anak dan orang tua murid, untuk usia anakanak usia dini dapat menggunakan fitur panggung Sekolah sebagai wadah dalam berkreasi. Tayangan siaran pada TV Sekolah berbeda dengan TV yang kita kenal pada umumnya, karena TV Sekolah didesain sesuai dengan kebutuhan sekolah itu sendiri, cara atau langkah-langkah yang dilakukan dalam men-dokumentasikan file pada perpustakaan digital TV Sekolah adalah sebagai berikut:

a) Membuat video setiap kegiatan yang dilakukan oleh guru, anak-anak atau orang tua murid sebagai dokumentasi.

b) Video-video yang telah disiapkan di-upload atau dikirim ke chanel you tobe sekolah.

c) Setelah itu menyalin atau mengkopy link youtobe, lalu diplaylist di TV Sekolah.

Dalam chanel TV Sekolah terdapat Kontributor dan Verifikator. Kontributor bertugas untuk mengupload video dan diverifikasi oleh bagian verifikator.

\section{SIMPULAN DAN SARAN}

\section{A. Simpulan}

Perpustakaan Digital TV Sekolah merupakan fitur TV Sekolah yang menyajikan tayangan-tayangan video edukatif yang dibuat siswa dan guru untuk didokumentasikan ke dalam file dokumen Perpustakaan TV Sekolah yang dapat diakses oleh siswa-siswa maupun guru-guru bahkan oleh orang tua siswa itu sendiri bahkan juga dapat diakses oleh sekolah lain Dengan adanya Chanel TV Sekolah, maka dapat memudahkan bagi Lembaga TK Insan Profesi sekolah untuk mendokumentasikan semua Program kegiatan yang dilakukan oleh guru, maupun siswa melalui video-video kegiatan yang tersimpan dalam file atau dokumen perpustakaan Digital TV Sekolah, yang dapat diakses setiap waktu, setiap saat dibutuhkan oleh sekolah.

\section{B. Saran}

Harapan penulis semoga implementasi Perpustkaan Digital TV Sekolah di TK Insan Profesi Baubau bisa berkembang ke depannya, sehingga file-file video tidak perlu lagi disimpan dalam perangkat HP atau leptop tapi sudah didokumentasikan ke dalam dokumen Fitur Perpustakaan Digital TV Sekolah, sehingga dapat memudahkan bagi siapa saja untuk mengakses video-video kegiatan guru, murid maupun orang tua mu TK Insan Profesi, sampai kapan pun. Ucapan terimakasih yang sebesar-besarnya kepada semua pihak yang telah memberikan dukungan baik guru, orang tua murid maupun anak-anak yang selalu dengan antusias melakukan kegiatan, terkhusus kepada ibu Dr. Sri Watini, M.Pd sebagai innovator / CEO TV Sekolah sekaligus sebagai dosen pengampu mata kuliah Inovasi dan Kreativitas Program Pasca Sarjana PAUD Universitas Panca Sakti Bekasi yang selalu membimbing, mensuport dan menularkan ilmu yang begitu bermanfaat kepada kami sebagai mahasiswa, semoga menjadi ladang amal baik di dunia dan di akhirat. Aamiin.

\section{DAFTAR RUJUKAN}

Arief Budiman (2017) :Industri Media Televisi: https://www.academia.edu/9195683/indus tri_media_televisi

https://lib.umm.ac.id/article/detail/201511171 03926/pengertian-perpustakaan-digitaldigital-library-e-library/

https://tvsekolah.id/home/berita/yb7lsd13fr9

https://bpmtv.kemdikbud.go.id

Watini, S, dkk, (2020) TV Sekolah : Karya Rekaman Suara atau bunyi : HKI Kemenhumham atas nama dengan nomor Pencacatan 000224874 Tertanggal 1 Juli 2020

Watini, S, dkk. (2020) TV Sekolah: Hak Cipta terdaftar hak paten no. ECOO202020424, 15 Oktober 2020

Watini, S. Dkk. (2020) PSE: TV Sekolah Wahana Kreasi dengan nomor 002009.01/DJAI.PSE/01/2022, 25 Januari 2022. Tvsekolah.id

Watini, S. (2020) Implementasi Model Pembelajaran Sentra pada TK Labschool STAI Bani Saleh Bekasi: Journal Obsesi Pendidikan anak Usia Dini 4 (1) 2020. https://obsesi.or.id/index.php/obsesi/article/ view $/ 190$ 